\title{
Hypertension and the prevention of coronary heart death in general practice
}

\author{
JULIAN TUDOR HART \\ M.B., D.C.H., M.R.C.P., F.R.C.G.P. \\ Glyncorrwg Health Centre, South Wales
}

\begin{abstract}
Summary
A major attack on the main risk factors of coronary heart disease is essential in order to control it.

In general practice, there is a real opportunity to control high blood pressure and smoking; unfortunately coronary risk factors are closely related to social class and unemployment. Major new strategies will be needed both by government and the medical profession in order to achieve a reduction in the commonest single cause of death in the U.K.
\end{abstract}

\section{Introduction}

We need to consider whether we are winning or losing the war against premature death from coronary heart disease.

To this end, we must assess (1) the effectiveness of our weapons, both in the optimal conditions of clinical trials, and in real conditions in the field; (2) how both weapons and personnel are deployed by our medical and health strategists; (3) how the weapons are used tactically in the front line; and finally, (4) the general balance of forces and social context within which the war is being fought.

\section{The weapons-blood pressure control by drugs}

Can control of high blood pressure reduce mortality or morbidity from coronary heart disease? Table 1 combines the results of randomized controlled trials of antihypertensive treatment (Hamilton, Thompson and Wisniewski, 1964; Veterans Administration, 1967, 1970; McFate Smith, 1978; Mitchell Perry et al., 1978; Helgeland, 1980; Australian Blood Pressure Management Committee, 1980). These trials show that community blood pressure control contributes almost nothing directly to reduction of myocardial infarction, although the effect on stroke (and on heart failure, renal failure, and eye damage) is dramatic, and is the real justification for mass programmes of ascertainment and treatment.

TABLE 1. Aggregate results of seven randomized controlled trials of antihypertensive treatment; both sexes, all ages and degrees of hypertension, fatal and non-fatal events
Treated Controls

\begin{tabular}{|c|c|c|c|}
\hline \multicolumn{3}{|l|}{$\begin{array}{l}\text { Myocardial infarcts } \\
\text { and sudden death }\end{array}$} & \\
\hline Hamilton et al. (1964) & 1 & 3 & \\
\hline VA (1967) & 0 & 3 & \\
\hline VA (1970) & 13 & 11 & \\
\hline USPHS pilot, McFate Smith (1978) & 8 & 7 & \\
\hline VA-NHLBI pilot, Mitchell Perry & & & \\
\hline et al. (1978) & 8 & 5 & \\
\hline ANBPS, Australian BPMC (1980) & 33 & 33 & \\
\hline Oslo, Helgeland (1980) & 17 & 11 & \\
\hline Total & 80 & 73 & \\
\hline Stroke & & & \\
\hline Hamilton et al. (1964) & 3 & 7 & \\
\hline VA (1967) & 1 & 3 & \\
\hline VA (1970) & 5 & 20 & \\
\hline USPHS pilot (1978) & 0 & 2 & \\
\hline VA-NHLBI pilot (1978) & 0 & 0 & \\
\hline ANBPS (1980) & 3 & 6 & \\
\hline Oslo (1980) & 0 & 7 & \\
\hline Total & 12 & 45 & \\
\hline
\end{tabular}

Effective treatment of severe hypertension substitutes later death from coronary disease for early $\mathcal{N}$ mutilation or death by stroke (Breckenridge, Dollery N and Parry, 1970). All these trials initially used N thiazide diuretics but the use of beta-blockers (for 0 example in the current MRC trial) may change this conclusion.

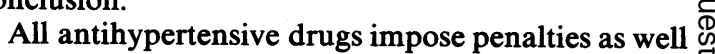
as benefits. On the evidence of the Australian trial and the side effects reported in the interim findings of 
the MRC trial, every doctor, and perhaps every patient, should decide whether six fewer deaths outweighs 65 more impotent men treated with propranolol, or 262 more impotent men treated with thiazides, in 14,000 patient-years of treatment (Peart, 1981). Those doctors who invariably ask their patients specifically about common side effects may partially escape this dilemma.

Does this mean that diagnosis and treatment of high blood pressure are useless weapons against coronary disease? Not at all-the effectiveness of treatment in preventing stroke makes the treatment of moderate and severe hypertension mandatory for that reason alone, and since hypertension rarely causes symptoms, the whole adult population, at least up to 70 years of age, has to be screened in order to find the 5-10\% who are in these categories. In the course of this work about three times as many people will be found with mild hypertension in the diastolic range $90-99 \mathrm{mmHg}$. On the evidence of the Australian trial, about half of these will fall below $90 \mathrm{~mm} \mathrm{Hg}$ within 2 years without any treatment at all, and there is no convincing controlled evidence that any of them should be treated with antihypertensive drugs, unless they show evidence of organ damage.

In our practice, the control of moderate and severe hypertension with antihypertensive drugs we have achieved does not seem to have contributed in any direct way to control of coronary heart disease. However, all hypertensives in our population are identified, all are offered treatment and/or follow-up. Ninety-one percent of them had been seen within the last 3 months at our last audit, and the mean pressure of the whole group fell from $199 / 119 \mathrm{mmHg}$ before treatment to $152 / 90 \mathrm{mmHg}$.

But there is much else we can do for them (apart from watching for rising pressure in a minority) which is directly relevant to prevention of coronary deaths.

\section{Other ways to reduce blood pressure and other risk factors}

Hypertensives of all grades are at high risk of myocardial infarction, and therefore a particularly favourable group for individualized counselling on reduction of other risk factors. Measures which might be taken in this group are: control of dietary fat and obesity, control of dietary sodium and potassium, and control of smoking. Doubts here centre less on the effectiveness of these measures, than on their feasibility. In Glyncorrwg we have been screening the whole adult population for blood pressure, height and weight, and smoking, since 1968, and have gradually developed systematic policies for intervention. From this we have learned many things, but have concentrated on two; control of smoking in everyone, but with particular attention to those with airways obstruction or high blood pressure; and/or control of hypertension in those with mean pressures (on three readings) diastolic $\geqslant 105$, revised in 1982 to $\geqslant 100 \mathrm{mmHg}$. Only recently have we begun to tackle obesity in a systematic way, and we have never attempted systematic control of hyperlipæmia, because this was beyond our resources. Although our choice may have been wrong, in view of our limited resources, we decided to choose these factors as priorities.

Acute reduction of dietary sodium to levels below 5 $\mathrm{g}(80 \mathrm{mmol})$ a day, over periods of 6 weeks or so, does not result in significant reduction of arterial pressure in mild hypertension (diastolic $90 \mathrm{mmHg}$ )(Watt et al., 1983; Puska et al., 1983; Silman et al., 1983) though there is good evidence that it does so at higher levels of pressure which normally require antihypertensive drugs (MacGregor et al., 1982). It has yet to be shown convincingly that patients find salt restriction to this level more tolerable than personalized medication. Lesser and more gradual reductions in dietary sodium, probably assisted by a gradual rise in dietary potassium, may be effective in shifting the entire distribution of arterial pressure down by a few millimetres of mercury, as suggested by Rose (1981), and would certainly be more tolerable, but this has yet to be shown by controlled studies. If this is confirmed, effective action must lie mainly at the level of national dietary planning which is now almost entirely discarded by our government, despite its great effectiveness during World War II.

Thirty-two percent of 80 hypertensives currently on antihypertensive drugs in our practice had a body mass index (metric weight/height ${ }^{2}$ ) $\geqq 30$, that is, $35 \%$ or more above ideal weight, which is the threshold for evidence of an independent effect of obesity on mortality. This was not significantly greater than the proportion in age- and sex-matched controls from the rest of our population. We are just beginning to tackle this problem systematically with the help of a dietitian, mainly through group work.

Table 2 shows the proportion of smokers among known hypertensives (diastolic blood pressure $\geqq 105$ $\mathrm{mmHg}$ through three readings) in 1968-70 (the time of our first total population screen) and in June 1983, and the proportion of smokers in an equal, randomly sampled age- and sex-matched group of the rest of the Glyncorrwg population. The proportions of smokers found by the General Household Survey for men and women in Social Class III (skilled manual workers) in the nearest available years, are shown for comparison (Central Statistical Office, 1981). The comparison is not exact, because the Glyncorrwg data under-represent younger age-groups.

In 1968, Glyncorrwg men had about the same smoking habits as skilled manual workers throughout 
TABLE 2. Cigarette smoking in a cohort of screened moderate/severe hypertensives in 1968 and 1983, compared with an equal number of age- and sex-matched controls randomly sampled from the same population

\begin{tabular}{|c|c|c|c|c|}
\hline & \multicolumn{2}{|c|}{ Smokers in $1968 / 70$} & \multicolumn{2}{|c|}{ Smokers in 1983} \\
\hline & $n$ & $(\%)$ & $n$ & $(\%)$ \\
\hline $\begin{array}{l}\text { Hypertensive men } \\
(n=56) \\
\text { Other men }\end{array}$ & 31 & 55 & 14 & 25 \\
\hline $\begin{array}{l}(n=56) \\
\text { GHS* }\end{array}$ & 33 & $\begin{array}{l}59 \\
57\end{array}$ & 19 & $\begin{array}{l}34 \\
48\end{array}$ \\
\hline $\begin{array}{l}\text { Hypertensive women } \\
(n=54) \\
\text { Other women }\end{array}$ & 18 & 33 & 8 & 15 \\
\hline $\begin{array}{l}(n=54) \\
\text { GHS }\end{array}$ & 27 & $\begin{array}{l}50 \\
47\end{array}$ & 21 & $\begin{array}{l}39 \\
43\end{array}$ \\
\hline $\begin{array}{l}\text { All hypertensives } \\
(n=110) \\
\text { All others } \\
(n=110)\end{array}$ & $\begin{array}{l}45 \\
60\end{array}$ & $\begin{array}{l}41 \\
55\end{array}$ & 22 & 20 \\
\hline
\end{tabular}
1980.

*GHS = General Household Survey, Social Class III, 1972 and

the U.K., women substantially less. The reduction in smoking in both hypertensives and others by more than half (to less than half the U.K. rate) is 3.5 times the standard error for hypertensives, and 2.9 times the standard error for others. However, though the reduction in hypertensives is greater than in the population as a whole, we have no convincing evidence that advice to hypertensives was much more effective than to the rest of the population.

Although this seems to argue against the value of identifying separately the hypertensive risk group, we have not drawn such a negative conclusion, for the following reasons.

Since the early 1970 s, we have tried not only to record smoking habits in our whole population from 16 years upwards, but also to personalize our advice by measuring and recording other risks, chiefly oral contraception, airways obstruction, diabetes, and family history of coronary disease and lung cancer, as well as hypertension. We believe that the more trouble we take to assess risks concretely in each patient, the better chance we have that the patient will act on advice. We have tried as far as possible to extend most consultations, whatever the complaint that initiates them, to include such assessments, and from time-to-time to reinforce such advice. This means, therefore, that hypertensives are not the only group receiving special attention, and it is not surprising that there is relatively little difference between the hypertensives and others.

\section{Multifactorial prevention of coronary heart disease}

We already understand that coronary heart disease does not have a single cause, but it seems to take longer to understand that its prevention is also multifactorial. Wars are not won by single weapons $\frac{\mathbb{D}}{\mathbb{Q}}$ or by a single arm of service. There is so far only oneexample of planned action within the community to prevent coronary disease, on a sufficient scale to give? conclusive results, and that is the North Karelize Project (Salonen et al., 1983). North Karelia, the province with the highest coronary mortality in? Finland in 1969, had a $24 \%$ reduction in coronarya mortality at ages 35-64 years in men, and a 51\% reduction in women, both more than twice as great asin other parts of Finland. There can be no reasonable doubt that this is mainly due to the plannec preventive programme based within the communitys integrated with primary medical care from healtho centres, and employing a wide range of locally $\stackrel{3}{\text {. }}$. recruited paramedical personnel.

We should pay particular attention to one out-o standing feature of the North Karelia Project. For thee first 5 years, it yielded no tangible results, in fact the decline in mortality in the province was less than ino other parts of Finland, to an extent that endangered continued support for the project. This will not surprise anyone with real experience of work within? communities, designed to change human behaviour The reason most experiments in behavioural change have lasted less than 2 years is simply that mosto research has been undertaken by young graduatest who only have funding for a year or two. It is क्षें impertinence to expect change in community customs, without getting to know people well enough to understand what those customs are. Change withing general practice is painful and difficult; but change $\frac{0}{2}$ without it is impossible. If health services have anything to contribute to health, we must start from $\frac{3}{3}$ where we are with the people we have. Profound changes are necessary at primary level (hospitals aref largely irrelevant to this problem), but they must not be expected to lead to rapid results.

Control of hypertension in British general practices. is probably better done than control of any other risk 3 . factor. Yet evidence from representative samples of GPs shows at least half our hypertensives are still not identified, half of those identified are not treated, ando half of those treated are not controlled (Hart, 1982) and this picture has hardly changed since the earlyo 1970s (Ritche and Currie, 1983). Serious planned $\bar{N}$. attacks on smoking and other risk factors have hardlyo even begun in British primary care, and certainly lag $N$ far behind what has been achieved for hypertension control.

The sad truth is that our strategists have no troops and our troops have no strategy. Ideas about control: of risk factors in the community have hitherto come almost entirely from hospital-based specialists, and 0 epidemiologists with a hospital rather than a generalo 
practice background. They have the will but not the means to put their ideas into effect. General practitioners and other health workers in primary medical care inherit professional and patient expectations that base nearly everything on response to presented demand. As demand remains high and resources remain inadequate, with an average of $5 \mathrm{~min}$ consulting time for each visit (Buchan and Richardson, 1973), planned search for needs has had a low priority. The techniques used at our health centre include extension of the average consultation to 8 $\mathrm{min}$, another estimated average $4 \mathrm{~min}$ for work delegated to a practice nurse, and conversion to structured A4 records requiring a total of over $300 \mathrm{hr}$ medical time. The iceberg of submerged precursor disease greatly outweighs the peak of episodic urgent demand. This fact is recognised by health strategists not personally involved in primary care, but they forget that prudent navigators do not find icebergs attractive! Few primary medical teams, already at full stretch in those areas which most need anticipatory care, are in a hurry to add to their burdens by attacking precursor states as well as endstage disease. If all GPs employed their full quota of two full-time equivalent paramedical staff for whom $70 \%$ of wage costs are reimbursed by the DHSS, instead of the present $15 \%$ or so who do so now, general practice might seriously undertake the shift to anticipatory community care which was recommended by the RCGP (1981a; b, 1983).

\section{Conclusions}

I am forced to conclude that for the most part, the war is simply not being fought. It is a phoney war in which governments trade profitably with the enemy, have no belief in ultimate victory, and remain content to leave the fighting to a few enthusiasts, when whole divisions should be engaged. Unlike America and Australia, we do not have (and cannot afford) a fee-paid service to encourage initiative, which might in any case be indiscriminate. But in its absence, we need leadership and organization; we have neither. Meanwhile, the iceberg grows. As fast as we chip away at its apex by bypass surgery, intensive care units, and coronary ambulances (and, by world standards, that is not very fast) more appears from the mass beneath, which depends not on these trivial events on the surface, but on its location in warm or cold seas. We are not getting warmer, but much, much colder. Virtually all known risk factors for coronary disease and death are associated with social class and the indicators of poverty in industrial societies. Coronary mortality is $26 \%$ higher in unskilled labourers than in professional men, and $152 \%$ higher in their wives (Rose and Marmot, 1981). Risk factors and mortality both follow the geography of poverty and unemployment, with the worst indices in Ulster, Scotland, South Wales, and the North of England (Shaper et al., 1981). Deaths ascribed to 'hypertensive disease' are strongly correlated with unskilled occupation and other indices of poverty (Charlton et al., 1983), and so are deaths from stroke (Hart, 1979). These figures relate to the days when we had only one million unemployed; what will happen to hypertension and to coronary mortality when the long-term effects of four or five million unemployed become apparent? In the upper Afan Valley we now have an unemployment rate close to $40 \%$, and that is on the eve of a new round of pit closures. We are winning a battle in Glyncorrwg, but, so far, we are losing the war because it is not being fought.

Among those unemployed are the primary paramedical workers of the future, who could extend our present primitive primary care teams from episodic attention to demand, to the anticipatory care of the whole of each community in the new dimensions of behavioral change. That will require social courage and imagination. Until those qualities are rediscovered, we shall continue to lose.

\section{Acknowledgments}

I am grateful to Dr Tim Helme for extracting the figures on obesity from our practice population.

\section{References}

Australian Blood Pressure Management Committee (1980) The Australian therapeutic trial in mild hypertension. Lancet, $\mathbf{i}$, 1261.

Breckenridge, A., Dollery, C.T. \& PARRY, E.H.O. (1970) Prognosis of treated hypertension; changes in life expectancy and causes of death between 1952 and 1967. Quarterly Journal of Medicine, NS39, 411.

BUCHAN, I.C. \& RICHARDSON, I.M. (1973) Time study of consultations in general practice. Scottish Home and Health Department, Edinburgh.

Central Statistical Office (1981) Social Trends 1982. HMSO, London.

Charlton, J.R.H., Hartley, R.M., Silver, R. \& Holland, W.W. (1983) Geographical variation in mortality from conditions amenable to medical intervention in England and Wales. Lancet, i, 691.

Hamilton, M., Thompson, E.N. \& Wisniewski, T.K.M. (1964) The role of blood pressure control in preventing complications of hypertension. Lancet, i, 235.

HART, J.T. (1979) Can we and do we prevent strokes by treating hypertension? Practitioner, 223, 662.

HART, J.T. (1982) Measurement of omission. British Medical Journal, 284, 1686.

Helgeland, A. (1980) Treatment of mild hypertension: a five-year controlled drug trial, the Oslo study. American Journal of Medicine, 69, 725.

MCFATE SMITH, W. (1978) Mild essential hypertension: benefit of treatment. Annals of the New York Academy of Sciences, 304, 74.

MCGregor, G.A., Markandu, N.D., Best, F.E., Elder, D.M., CAM, J.M., SAGnella, G.A. \& SQuires, M. (1982) Double-blind randomised crossover trial of moderate sodium restriction in essential hypertension. Lancet, i, 351. 
Mitchell Perry, H., Goldman, A.I., Lavin, M.A., Schnaper, H.N., Fitz, A.E., Frohlich, E.D., Steele, B. \& Richman, H.G. (1978) Evaluation of drug treatment in mild hypertension: VANHLBI feasibility trial. In: Mild hypertension: to treat or not to treat? (Eds Mitchell Perry, H. \& McFate Smith, W.), p. 267. New York Academy of Sciences, New York.

PEART, W.S. (1981) The problem of treatment in mild hypertension. Clinical Science, 61, 403s.

Puska, P., Iacono, J.M., Nissinen, A., Koryonen, H.J., Vartiainen, E., Pietinen, P., Dougherty, R., Leino, U., Mutanen, M., Moisio, S. \& Huttunen, J. (1983) Controlled randomised trial of the effect of dietary fat on blood pressure. Lancet, i, 1.

RITCHIE, L.D. \& CURRIE, A.M. (1983) Blood pressure recording by general practitioners in north-east Scotland. British Medical Journal, 286, 107.

ROSE, G.A. (1981) Strategy of prevention: lessons from cardiovascular disease. British Medical Journal, 282, 1847.

Rose, G.A. \& MARMOT, M.G. (1981) Social class and coronary heart disease. British Heart Journal, 45, 13.

Royal College of General Practitioners Working Party OF COUNCIL (1981a) Health and prevention in primary care. Report from general practice 18, RCGP, London.

IBID (1981b) Prevention of arterial disease in general practice. Report from general practice 19, RCGP, London.
IBID (1983) Promoting prevention. Occasional Paper 22. RCGP, London.

Salonen, J.T., Puska, P., Kottke, T.E., Tuomilehto, J. \& NisSinen, A. (1983) Decline in mortality from coronary heart $\varrho$ disease in Finland from 1969 to 1979. British Medical Journal, 286, . 1857.

Shaper, A.G., Pocock, S.J., Walker, M., Cohen, N.M., Wale, C.J. \& ThOMSON, A.G. (1981) British Regional Heart Study: cardiovascular risk factors in middle-aged men in 24 towns. British Medical Journal, 283, 179.

Silman, A.J., LoCKe, C., Mitchell, P. \& Humpherson, P. (1983) $\frac{\bar{\Phi}}{\mathrm{T}}$ Evaluation of the effectiveness of a low sodium diet in the $\mathbb{D}$ treatment of mild to moderate hypertension. Lancet, i, 1179.

VETERANS ADMINISTRATION STUDY GROUP ON ANTIHYPERTEN- ڤొ SIVE AGENTS (1967) Effects of treatment on morbidity in $\vec{\circ}$ hypertension: results of treatment in patients with diastolic. pressures averaging 115 through $129 \mathrm{mmHg}$. Journal of the $\overrightarrow{\vec{H}}$ American Medical Association, 202, 116.

IBID (1970) Effects of treatment on morbidity in hypertension:? results of treatment in patients with diastolic blood pressurese averaging 90 through $114 \mathrm{mmHg}$. Journal of the American Medical 3 . Association, 213, 1143.

WATt, G.C.M., EDWARDS, C., HART, J.T., HART, M., WALTON, P. ๑ \& FoY, C.J.W. (1983) Dietary sodium restriction for mild 8 hypertension in general practice. British Medical Journal, 286, 432. 